\title{
CHARACTER VALUES IN MACAPAT SONG
}

\section{Ellie Syafitri, Hanaan Rofiiqoh, Rifa Alimah, Muhamad Chamdani}

Universitas Sebelas Maret

elliesyafitri@student.uns.ac.id

\section{Article History}

accepted 30/09/2018

approved 12/10/2018

published 30/10/2018

\section{Keywords}

Values, characters, macapat songs

\begin{abstract}
The purpose of writing this article is (1) to examine the meanings that contained in the macapat song (2) to examine the values that found in the macapat song. Value is a benchmark that is considered true and a guide in community life in making a decision. The method that used in writing this article uses the literature study method. From the problems obtained, it can be concluded that there are character values from macapat mijil, kinanthi, dhandanggula, gambuh, durma, pangkur, and pocung. Character value is the quality of depicting human behavior that can be formed through education and the surrounding environment. The character values that can be taken from the macapat songs are loving peace, religious values, educational values, honesty, responsibility, discipline values, and high curiosity. Through macapat songs, students can apply the character values in daily life.
\end{abstract}

Social, Humanities, and Education Studies (SHEs): Conference Series https://jurnal.uns.ac.id/shes
p-ISSN 2620-9284 e-ISSN 2620-9292 


\section{PENDAHULUAN}

Seiring berkembangnya zaman pada era globalisasi ini, dilihat dari aspek kebudayaan banyak budaya tradisional mulai ditinggalkan. Hal ini dikarenakan masuknya pengaruh budaya dari barat dan kemajuan teknologi yang semakin canggih. Contoh budaya yang mulai luntur yakni tembang-tembang Jawa. Lunturnya tembangtembang Jawa disebabkan oleh maraknya peredaran lagu-lagu yang bersifat kurang mendidik untuk usia anak sekolah. Selain itu, tembang-tembang Jawa itu dianggap ketinggalan zaman. Hal ini diperkuat dengan banyaknya usia anak sekolah yang tidak tahu tentang tembang-tembang Jawa. Ada juga anak yang tahu tentang tembang jawa namun tidak mengetahui maksud dan isi yang terkandung dalam tembang-tembang Jawa tersebut. Padahal dalam budaya Jawa, nilai-nilai kehidupan masyarakat Jawa sangat pantas untuk dijadikan pedoman pengembangan karakter seseorang.pengembangan karakter menjadi sesuatu yang sangat penting dan strategis karena karakter seringkali diidentikkan dengan budi perkerti atau akhlak.

Tembang-tembang Jawa yang telah lahir sejak zaman kerajaan adalah hasil dari kebudayaan nenek moyang yang syarat akan nilai-nilai karakter. Tembang adalah nyanyian atau syair yang diberi berlagu untuk dinyanyikan. Selain untuk dinyanyikan menurut Setiyadi (dalam Gumilang 2017 : 67) tembang bisa dipakai sebagai sarana membangun kehalusan budi dan citarasa keindahan. Karena itu, jika di dalam lariklarik tembang itu disisipkan ajaran-ajaran budi perkerti yang luhur, maka dengan mudah dpat diingat-ingat dan diterapkan dalam kehidupan bermasyarakat.Tembang Jawa merupakan bagian dari puisi Jawa. Secara garis besar, puisi Jawa dapat diklasifikasikan menjadi tiga kelompok, yakni puisi Jawa lama, puisi Jawa baru, dan puisi Jawa modern. Puisi Jawa lama terdiri atas puisi Jawa kuno (yang biasa disebut, kakawin, sekar ageng) dan puisi Jawa Tengahan (disebut dengan nama kidung, sekar tengahan). Puisi Jawa baru meliputi tembang macapat (sekar alit dan parikan); sedangkan yang termasuk puisi Jawa modern adalah geguritan dantembang-tembang Jawa, seperti tembang dolanan, tembang campursari, keroncong, dan lagu-lagu pop Jawa (Sumarlam, 2016: 55). Menurut Sundari (dalam Budiono dan Nara, 2017: 1345) pada umumnya macapat diartikan sebagai maca papat papat (membaca empatempat), yaitu cara membaca terjalin tiap empat suku kata.

Menurut Purna (dalam Budiono dan Nara, 2017: 1346) tembang macapat merupakan bagian penting dari budaya Indonesia utamanya Jawa. Kandungan isinya memiliki berbagai fungsi sebagai pembawa amanat, sarana penuturan, penyampaian ungkapan rasa, media penggambaran suasana, penghantar teka teki, media dakwah, alat pendidikan serta penyuluhan, dan sebagainya. Setiap bait macapat mempunyai baris kalimat yang disebut gatra, dan setiap gatra mempunyai sejumlah suku kata (guru wilangan) tertentu, dan berakhir pada bunyi sajak yang disebut guru lagu.

Menurut Gumilang (2017: 64) sebagai suatu pesan, macapat mempunyai ciri dan makna sendiri-sendiri sesuai tujuan yang dimaksudkan. Hal ini dapat diartikan bahwa setiap satu serat tembang macapat mempunyai tujuan dan makna tersendiri serta berbeda satu sama lainnya yang secara langsung membuat pesan yang berbeda-beda pula. Sesuai dengan maksud penciptanya. Berdasarkan jenis dan urutannyatembang macapat ini sebenarnya menggambarkan perjalanan hidup manusia, tahap-tahap kehidupan manusia dari mulai alam ruh sampai dengan meninggalnya. Menurut Sawarna (dalam Gumilang, 2017: 64) rangkaian urut-urutan dari jenis tembang macapat yaitu mijil, kinanthi, sinom, asmarandhana, dhandhanggula, gambuh, maskumambang, dhurma, pangkur, megatruh, dan pocung. Tiap-tiap tembang macapat mempunyai tema atau watak. Dalam penggunaannya 
harus selaras dan serasi dengan isinya. Keselarasan inilah yang menciptakan keindahan pada tembang yang dilantunkan.

Melalui tembang macapat mijil, kinanthi, dhandanggula, gambuh, durma, pangkur, dan pocung kita dapat mempelajari atau mengambil beberapa nilai karakter seperti nilai cinta kedamaian, nilai religius, nilai pendidikan, nilai kejujuran, nilai tanggung jawab, nilai kedisiplinan, dan rasa ingin tahu yang tinggi. Di masa sekarang, saat budaya tradisonal mulai ditinggkalkan, dengan mempelajari nilai-nilai karakter melalui tembang macapat tersebut maka budaya tradisional akan tetap terjaga dan nilai-nilai karakter dapat terbentuk kemudiaan menjadi suatu kebiasaan yang baik.

\section{METODE}

Metode yang digunakan adalah studi kepustakaan, menurut Nazir (2003) mengemukakan bahwa "Studi kepustakaan adalah teknik pengumpulan data dengan mengadakan studi penelaahan terhadap buku-buku, litertur-literatur, catatan-catatan, dan laporan-laporan yang ada hubungannya dengan masalah yang dipecahkan.". Peneliti melakukan kajian yang berkaitan dengan teori yang terkait dengan topik penelitian, mengumpulkan informasi sebanyak-banyaknya dari kepustakaan yang berhubungan dengan nilai-nilai karakter yang dapat dikembangkan melalui tembang macapat.

\section{HASIL DAN PEMBAHASAN}

Nilai berasal dari bahasa latin yaitu valere yang berarti berguna, mampu akan, berdaya, berlaku, sehingga nilai dapat diartikan sebagai sesuatu yang dipandang baik, bermanfaat dan paling benar menurut keyakinan seseorang atau sekelompok orang. Nilai adalah kualitas suatu hal yang menjadikan hal itu disukai, diinginkan, dikejar, dihargai, berguna dan dapat membuat orang yang menghayatinya menjadi lebih bermartabat (Adisusilo, 2014: 56). Menurut Baihaqi (dalam Nugrahastuti dkk, 2016: 266) nilai adalah konsep-konsep umum tentang sesuatu yang dianggap baik, patut, layak, pantas yang keberadaannya dicita-citakan, diinginkan, dihayati, dan dilaksanakan dalam kehidupan sehari-sehari dan menjadi tujuan kehidupan bersama didalam kelompok masyarakat tersebut, mulai dari unit kesatuan, sosial terkecil hingga suku, bangsa, dan masyarakat internasional.

Istilah karakter berasal dari bahasa Yunani, charassein, yang berarti to engrave (mengukir). Dengan demikian, membentuk karakter diibaratkan seperti mengukir diatas batu yang pelaksanaannya tidak mudah. Dari makna asal tersebut kemudian pengertian karakter berkembang menjadi tambah khusus atau pola perilaku (an individual's patten of behaviour...his moral contituation)(Kosim, 2011). Menurut Gordon W.Allport (dalam Narwanti,2011: 2) karakter merupakan suatu organisasi yang dinamis dari sistem psiko-fisik individu yang menentukan tingkah laku dan pemikiran individu secara khas. Interaksi psiko-fisik mengarahkan tingkah laku manusia. Karakter bukan sekadar sebuah kepribadian (personality) karena karakter sesungguhnya adalah kepribadian yang ternilai (personality evaluated). Menurut Sudirman (dalam Indrastoeti, 2016: 286) karakter merupakan nilai-nilai perilaku manusia yang berhubungan dengan Tuhan yang Maha Esa, diri sendiri,sesama manusia, lingkungan dan kebangsaan yang terwujud dalam pikiran, jika perasaan, perkataan, dan perbuatan, berdasarkan normanorma agama, hukum, tata krama, budaya dan adat istiadat.

Character is the foundation of self development, Character formation requires the development of traits such as purity, perseverance, faith, sincerity, obedience, fortitude, veneration, humanistic tendency, etc (Shrivastava, 2017). Character education is essential for building a moral society, and it is the conscious effort to 
cultivate virtue. The psychological components of character education encompass the cognitive, affective, and behavioral aspects of morality such as, moral knowing, moral feeling, and action (Lickona in Chowdhury, 2016).

Dari uraian pengertian nilai dan karakter menurut para ahli di atas dapat disimpulkan bahwa nilai karakter adalah kualitas penggambaran tingkah laku manusia yang dapat dibentuk melalui pendidikan dan lingkungan sekitar yang berhubungan dengan Tuhan yang Maha Esa, diri sendiri, sesama manusia, lingkungan, serta kebangsaan.

Pembentukan karakter salah satunya dapat melalui tembang macapat. Diantaranya yaitu melalui tembang macapat Mijil, Kinanthi, Dhandanggula, Gambuh, Durma, Pangkur dan Pocung.

\section{Nilai Cinta Kedamaian}

Mijil merupakan ilustrasi proses kelahiran manusia, mijil/ brojol/mencolot dan keluarlah jabang bayi bernama manusia.

Dedalane kuna lawan sekti

(jalan yang baik untuk menuju kesaktian)

Kudu andhap asor

(harus rendah hati)

Wani ngalah ndhuwur wekasane

(bersikap mengalah lebih tinggi kedudukannya)

Tumungkula yen dipun dukani

(lebih baik diam bilamana sedang dimarahi)

Bapak den simpangi

(perihal yang buruk dihindari)

Ana catur mungkur.

(semua perkataan tidak dihiraukan)

Poma kaki podo dipun eling

(tingkah laku harus diperhatikan)

Ing pitutur ingong

(di perkataan dan perbuatan)

Sira uga satriya arane

(bertindak yang adil)

Kudu anteng jatmiko ing budi

(harus anteng di tingkah laku)

Ruruh sarta wasis

(berpengetahuan tinggi)

Samubarangipun

(segala galanya)

Makna yang terdapat dalam tembang macapat Mijil yaitu menggambarkan perilaku utama yang harus dilakukan manusia dalam menjalani hidup. Nilai karakter yang terkandung dalam tembang macapat mijil yaitu cinta kedamaian, yang berarti dalam hidup harus senantiasa menjunjung tinggi rasa perdamaian, saling toleransi antar sesama, bertindak adil, dan bertingkah laku sesuai aturan dan norma yang berlaku.

\section{Nilai Religius}


Kinanthi artinya masa pembentukan jati diri dan meniti jalan menuju cita-cita.

Puniku nugraha agung

(bahwa sastra merupakan anugrah agung)

Wruh rahsa marang Hyang Oti

(dalam mengenal bersatunya rasa ketuhanan)

Tan kenging yen winedharna

(yang tak dapat dijelaskan)

Wit sastra tan nana muni

(pohon sastra tak ada yang berbunyi)

Liyane kang sastra cetha

(kecuali sastra cetha)

Lire cetha wus anunggil

(arti cetha telah menyatu)

Nunggil rahseng Hyang Mulku

(bersatunya rasa dengan Tuhan Maha Diraja)

Kang sipat Rabul Ngalamin

(yang bersifat merajai alam semesta)

Kang mengkono sabuana

(seperti itulah seluruh jagat raya)

Alam sahir alam kabir

(kecil dan alam besar)

Titinen kang Iwih tetela

(diteliti dengan lebih jelas)

Purbaning slira pribadi

(diciptakannya dirimu sendiri)

Nilai karakter yang terdapat dalam tembang Kinanthi yaitu sebagai manusia seyogyanya mendekatkan diri kepada sang Pencipta. Menyadari sepenuhnya bahwa kuasa seluruh alam semesta tidak lepas dari campur tangan sang Pencipta. Maka kita diwajibkan untuk menjauhi larangan-Nya dan menjalankan perintah-Nya.

\section{Nilai Pendidikan}

Dhandanggula menggambarkan kehidupan yang telah mencapai tahap kemapanan sosial, kesejahteraan telah tercapai, cukup sandang pangan dan papan (serta terntunya terbebas dari hutang piutang) menurut Sawarna (dalam Gumilang $2017: 64)$.

Werdi ingkang wasita jinarwi

(arti dari sebuah petuah)

Wruh ing kukum iku watekira

(agar mengetahui kaidah karena akan membentuk sifat)

Adoh marang kanisthane

(jauh dari sifat tercela)

Pamicara puniku

(perkataan itu)

Weh resepe ingkang miyarsi

(dapat diresapi oleh pendengarnya)

Tata krama puniku

(tata krama itu ) 
Ngedohken panyendu

(menjauhkan dari cercaan)

Kagunan iku kinarya

(pengetahuan itu untuk)

Ngupa boga dene kalakuan becik

(mencari nafkah dan tingkah laku baik)

Weh rahayuning raga

(memberi keselamatan hidup)

Lamun sira ameguru kaki

(jika engkau meminta nasihat dariku)

Amiliha manungsa sanyata

(pilihlah manusia sejati)

Ingkang becik martabate

(yang baik martabatnya)

Sarta weruh ing ukum

(serta mengenal hukum)

Kang ibadah lan kang wirangi

(yang taat beribadah dan menjalankan ajaran agama)

Sukur oleh wong tapa ingkang wus amungkul

(apalagi mendapat orang suka perihatin yang sudah mumpuni)

Tan gumantung liyan

(yang tak tergantung orang lain)

Iku wajib guronana kaki

(kepadanyalah engkau wajib berguru)

Sartane kawruhanana

(serta belajar kepadanya)

Nilai karakter yang terdapat dalam tembang Dhandanggula yakni hendaklah kita belajar dari orang yang sudah tinggi ilmunya, paham tentang hukum dan taat beribadah menurut agama dan kepercayaannya. Belajar bukan hanya di instansi saja tetapi belajar juga bisa di manapun. Contoh orang yang dapat kita jadikan panutan antara lain guru, dosen, para ulama, para kyai dan lain-lain.

\section{Nilai Kejujuran}

Aja kanti kabanjur

(jangan sampai terlanjur)

Barang polah ingkang nora jujur

(bertingkah polah yang tidak jujur)

Yen kebanjur sayekti kojur tan becik

(jika terlanjur tentu akan celaka dan tidak baik)

Becik ngupaya iku

(lebih baik berusahalah)

Pitutur ingkang sayektos

(mengikuti ajaran yang sejati)

Nilai karakter yang terdapat dalam tembang Gambuh yaitu nilai kejujuran. Kejujuran merupakan salah satu nilai penting karena memiliki peran dalam pembentukan karakter bangsa, untuk menanamkan kejujuran bukan hal yang mudah, perlu waktu yang lama dan di jadikan kebiasaan secara terusmenerus, sehingga nilai kejujuran harus dipupuk sejak dini. 


\section{Nilai Tanggung Jawab}

Sebagai wujud dari rasa syukur kita kepada Allah, maka kita harus sering berderma, durma berasal dari kata darma atau sedekah berbagi kepada sesama.

Lamon dika epasrae panggabayan

(jika kamu mendapat beban pekerjaan)

Ampon mare apeker

(sudah selesai dipikir)

Terang ka'eko'na

(tentang seluk beluknya kerja)

Ad janji maranta'a

(usaha untuk menyelesaikan)

Pon pon brinto taronggoi

(jika demikian haruslah serius)

Anggap tanggungan

(bekerja dengan penuh tanggung jawab)

Ma'ta'malo da'oreng

(bekerja dengan penuh tanggung jawab agar tidak mengecewakan orang)

Nilai karakter yang terdapat dalam tembang durma yaitu selalu bertanggung jawab dalam mengemban amanah. Apapun resiko yang ditanggung ke depannya, tetap bertanggung jawab dengan apa yang dilakukan. Dengan tanggung jawab, diharapkan mampu memberikan hasil akhir yang maksimal dan tidak mengecewakan.

\section{Nilai Kedisiplinan}

Pangkur atau mungkur artinya menyingkirkan hawa nafsu angkara murka, nafsu negatif yang menggerogoti jiwa.

\section{Kang sekar pangkur winarna}

(tembang pangkur yang diceritakan)

Lelabuhan kang kanggo ing wong urip

(darma bukti untuk kehidupan manusia)

Ala lan becik puniku

(buruk dan baiknya itu)

Prajoga kawruhana

(sebaiknya engkau ketahui)

Adat waton puniku dipun kadulu

(adat dan aturan harus dipahami)

Miwah ta ing tata krama

(juga tentang tata krama)

Den kaesti sijang latri

(selalu dicari siang dan malam)

Nilai karakter yang terdapat dalam tembang Pangkur yaitu kedisiplinan, kedisiplinan merupakan perilaku yang menunjukkan taat dan patuh pada aturan. Dengan kedisiplinan akan membentuk pribadi yang lebih terkontrol sehingga tercipta kehidupan yang terarah. 


\section{Rasa Ingin Tahu}

Ngelmu iku kelakone kanthi laku

(ilmu itu diperoleh melalui perjuangan)

Lekase lawan kas

(dimulai dengan kemauan)

Tegese kas nyantosani

(kemauan untuk menyejahterakan sesama)

Setiap budya pangekese dur angkara

(tabah sehingga dapat menaklukkan semua tantangan)

Angkara gung geng angga anggung gumulung

(kejahatan besar didalam tubuh kuat menggelora)

Gegolonganira

(menyatu dengan diri sendiri)

Triloka lekeri kongsi

(menjangkau hingga tiga dunia)

Yen den umbar ambabar dadi rubeda

(jika dibiarkan akan berkembang menjadi bencana)

Nilai karakter yang terdapat dalam tembang Pocung yaitu berusaha mencari ilmu apapun dan bagaimanapun kondisinya. Harus ada kemauan, kemampuan dan pejuangan.

\section{SIMPULAN}

Berdasarkan pembahasan dapat disimpulkan bahwa terdapat nilai-nilai karakter yang terkandung dalam macapat Mijil, Kinanthi, Dhandanggula, Gambuh, Durma, Pangkur dan Pocung. Bahwa nilai karakter adalah kualitas penggambaran tingkah laku manusia yang dapat dibentuk melalui pendidikan dan lingkungan sekitar. Diantaranya terdapat nilai Cinta Kedamaian, Nilai Religius, Nilai Pendidikan, Nilai Kejujuran, Nilai Tanggung Jawab, Nilai Kedisiplinan, dan Rasa Ingin Tahu.

Dengan demikian, melalui tembang macapat selain terdapat nilai-nilai karakter yang dapat dipelajari sekaligus membantu melestarikan budaya daerah khususnya tembang Jawa yang mulai luntur dikalangan anak usia sekolah zaman sekarang.

\section{DAFTAR PUSTAKA}

Adisusilo, S. 2014. Pembelajaran Nilai Karakter (Konstruktivisme Dan VCT sebagai Inovasi Pendekatan Pembelajaran Efektif). Jakarta: Rajawali Press

Budiono, H Dan Nara S. 2017. Pendidikan Nilai dalam Tembang Macapat dan Dhandanggula. Jurnal Penelitian Pendidikan Vol. 9 No. 1, 1311-1374

Chowdury, M. 2016. Emphasizing Morals, Values, Ethics, And Character Education In Sceince Education And Sceince Teaching. Australia. The Malaysian Online Journal of Educational Sceince Volume 4 - Issue 2.

Gumilang GS. 2017. Internalization Of Philosophical Value "Tembang Macapat" In Guidace and Counseling. Jurnal Proseding SNBK. Vol 01 No 1, 62-77

Indrastoeti, Jenny. 2016. Penanaman Nilai-Nilai Karakter Melalui Implementasi Pendidikan Karakter di Sekolah Dasar. Prosiding Seminar Nasional Inovasi Pendidikan Inovasi Pembelajaran Berbasis Karakter dalam Menghadapi 
Masyarakat Ekonomi ASEAN. Diunduh pada 19 September 2018 dari Https://Jurnal.Fkip.Uns.Ac.Id/Index.Php/Snip/Article/View/8944

Narwanti, S. 2011. Pendidikan Karakter. Yogyakarta: Familia

Nazir, Muhammad.(2003). Metode Penelitian. Jakarta: Ghalia Indonesia.

Nugrahastuti, dkk. 2016. Nilai-Nilai Karakter pada Permainan Tradisional. Prosiding Seminar Nasional Inovasi Pendidikan Inovasi Pembelajaran Berbasis Karakter dalam Menghadapi Masyarakat Ekonomi ASEAN. Diunduh pada tanggal 19 September 2018 jurnal.fkip.uns.ac.id/index.php/snip/article/download/8942/6503

dari

Kosim, M. 2011. Urgensi Pendidikan Karakter. KARSA Vol IXI No 1, 86-92.

Shrivastava, S K. 2017. Promotion of Moral Values Through Education. USA. International Journal of Research in Social Sceince Vol. 7 Issue 6.

Sumarlam. 2016. Revitalisasi Nilai Tembang-Tembang Jawa Upaya Membangun Karakter Generasi Muda Bangsa Indonesia. Diakses Pada 11 September 2018 dari Http://Jurnal.Fib.Uns.Ac.Ad//Index.Php/Lingustika_Jawa/Article/View/78 